\title{
O Legado Estruturalista em Lacan: Clínica e Diagnóstico da Psicose
}

\author{
Samira Pontes \\ Roberto Calazans \\ Universidade Federal de São João del-Rei, MG, Brasil. Universidade Federal de São João del-Rei, MG, Brasil.
}

\begin{abstract}
Resumo: A interrogação que move este trabalho é se a herança estruturalista na clínica lacaniana das psicoses estaria ultrapassada devido aos desdobramentos dos últimos ensinamentos de Lacan. Nessa direção, este artigo tem como objetivo apresentar algumas contribuições do estruturalismo à clínica lacaniana da psicose, tendo como chave de análise o chamado "diagnóstico estrutural". Foi com o ensino de Lacan que o diagnóstico diferencial, herdeiro de Freud, passou a ser qualificado como "estrutural" ao destacar a distinção das três grandes estruturas: neurose, perversão e psicose. A justificativa para a escolha da tônica do diagnóstico estrutural para a proposta de investigação do legado estruturalista em Lacan tem como base a evidência de duas vertentes que acabariam por impor alguns questionamentos à validade do diagnóstico apoiado na distinção estrutural atualmente: os chamados novos sintomas e o movimento de pluralização do Nome-do-Pai. Nesse sentido, admite-se que um breve retorno às principais contribuições do diálogo lacaniano com o estruturalismo na década de 1950 forneça considerações importantes para enriquecer o debate e esclarecer se essa herança estruturalista na clínica das psicoses estaria ultrapassada, ensejando, assim, o valor epistêmico da discussão para o campo da Psicologia como ciência. Não obstante, destaca-se a importância das questões atuais que circunscrevem o campo diagnóstico para a abordagem do sofrimento psíquico.
\end{abstract}

Palavras-chave: Psicanálise, Estruturalismo, Diagnóstico, Psicose

\section{The Structuralist Legacy in Lacan: Clinical and Diagnostic of Psychosis}

\begin{abstract}
The question that moves this work is whether the structuralist inheritance in the Lacanian clinic of psychoses would be overtaken due to the unfolding of Lacan's later teachings. In this sense, this article aims to present some of the structuralism's contributions to the Lacanian clinic of psychosis, by the analysis of the so-called 'structural diagnosis'. It was with Lacan's teachings that the differential diagnosis, heir to Freud, was described as "structural" to highlight the distinction of three major structures: neurosis, perversion and psychosis. The reason for choosing structural diagnosis for the research proposal of the structuralist legacy in Lacan is based on the evidence of two aspects that would eventually impose some questions on the validity of the diagnosis based on the current structural distinction: the so-called new symptoms and the pluralization of the Name-of-the-Father. In this sense, it is accepted that a brief return to the main contributions of Lacanian dialogue with structuralism in the 1950s provides important considerations to enrich the debate and to clarify if this structuralist heritage in the clinic of psychoses would be overtaken, justifying the value of the epistemic discussion for the field of Psychology as a science. Nevertheless, the importance of the current issues that circumscribe the diagnostic field for the approach to psychic suffering is highlighted.
\end{abstract}

Keywords: Psychoanalysis, Structuralism, Diagnosis, Psychosis 


\title{
El Legado Estructuralista en Lacan: Clínica y Diagnóstico de la Psicosis
}

\begin{abstract}
Resumen: La interrogación que mueve este trabajo es si la herencia estructuralista en la clínica lacaniana de las psicosis estaría sobrepasada debido a los desdoblamientos de las últimas enseñanzas de Lacan. En esta dirección, este artículo tiene como objetivo presentar algunas contribuciones del estructuralismo a la clínica lacaniana de la psicosis, teniendo como clave de análisis el llamado 'diagnóstico estructural'. Con la enseñanza de Lacan, el diagnóstico diferencial, heredero de Freud, pasó a ser calificado como "estructural” al destacar la distinción de las tres grandes estructuras: neurosis, perversión y psicosis. La justificación de la elección de la tónica del diagnóstico estructural para la propuesta de investigación del legado estructuralista en Lacan tiene como base la evidencia de dos vertientes que acabaría por imponer algunos cuestionamientos a la validez del diagnóstico apoyado en la distinción estructural actualmente: los llamados nuevos síntomas y el movimiento de pluralización del Nombre-del-Padre. En ese sentido, se admite que un breve retorno a las principales contribuciones del diálogo lacaniano con el estructuralismo en la década de 1950 proporciona consideraciones importantes para enriquecer el debate y aclarar si esa herencia estructuralista en la clínica de las psicosis estaría sobrepasada, dando así el valor epistémico de la discusión al campo de la Psicología como ciencia. No obstante, se destaca la importancia de las cuestiones actuales que circunscriben el campo diagnóstico para el abordaje del sufrimiento psíquico.
\end{abstract}

Palabras clave: Psicoanálisis, Estructuralismo, Diagnóstico, Psicosis

\section{Introdução}

Estaria a herança estruturalista na clínica lacaniana das psicoses ultrapassada? Essa questão é decorrente da grande discussão na psicanálise lacaniana a propósito do que seria o impacto do último ensino de Jacques Lacan sobre a clínica das psicoses. O último ensino de Lacan, por vezes chamado de "segunda clínica", compreende formulações que parecem retificar as de seu primeiro ensino ou, pelo menos, dar-lhes outras formas de mostração, como é o uso que o autor faz da topologia dos nós a partir da década de 1970. Nesse jogo de continuidades e descontinuidades característico do ensino de Lacan, discute-se com frequência o alcance da validade da influência das formulações estruturalistas presente em sua primeira clínica.

Na década de 1950, Lacan encontrou no movimento do estruturalismo princípios norteadores para seu projeto de retorno a Freud e fundamentação da função e campo da linguagem na Psicanálise, donde saíram noções basilares como: o inconsciente é estruturado como uma linguagem; o sujeito é efeito da articulação significante e a primazia do registro do simbólico. Também é notório nesse período a formalização da clínica da psicose e a distinção entre as estruturas clínicas: neurose, psicose e perversão. Nessa direção, o diagnóstico ganha, então, a alcunha "estrutural", que, mais que um simples qualificador, representa a baliza orientadora na clínica.

A partir da década de 1960, é patente o redirecionamento no ensino lacaniano para questões além dos ditames da linguagem. Ganham destaques temas como a pluralização do Nome-do-Pai, a escrita do gozo no corpo e o ineliminável do registro do real, haja vista o crescente envolvimento do autor com a Matemática e a topologia dos nós. As formulações anteriores recebem novos contornos teóricos, como, por exemplo, a noção de sinthoma. Diante das reformulações e inovações conceituais, há um crescente questionamento a respeito de qual seria o impacto do último ensino de Lacan sobre a clínica das psicoses. De modo específico, a herança estruturalista estaria ultrapassada, tendo em vista as reformulações da segunda clínica lacaniana?

Diante desse cenário, o objetivo deste artigo é apresentar algumas contribuições do estruturalismo à clínica lacaniana da psicose, tendo como foco a questão do diagnóstico estrutural. Entretanto, intentar estabelecer o legado estruturalista em Lacan é um trabalho demasiadamente extenso, logo, necessita de um recorte. Desse modo, foi escolhido o diagnóstico 
estrutural como chave de análise, pois, dentro desse cenário de discussão sobre as ressonâncias do último Lacan na clínica das psicoses, o chamado diagnóstico estrutural estaria no cerne do debate em relação à sua validade por duas vertentes que acabariam por colocar em xeque a relevância da distinção estrutural: a emergência dos ditos "novos sintomas" - quadros sintomatológicos que não responderiam mais à distinção clássica entre neurose/psicose, impondo dificuldades a um diagnóstico estrutural preciso; e a pluralização do Nome-do-Pai, uma vez que a coordenada diagnóstica teve como ponto de partida para Lacan a presença ou ausência desse operador fundamental.

Aponta-se duas direções que fundamentam a relevância desta pesquisa: a primeira seria a importância da discussão epistêmica sobre o valor do estruturalismo na conceituação das psicopatologias a partir da Psicanálise. Essa discussão implica em aproximações e afastamentos entre as contribuições do estruturalismo e a Psicanálise na atualidade. A segunda repousaria sobre uma questão polêmica no campo da psicopatologia: a construção do diagnóstico. Sabe-se que revisitar as contribuições do estruturalismo no ensino lacaniano implica na fundamentação das bases do diagnóstico da psicose. Não obstante, a temática do diagnóstico é atual e relevante para o campo do sofrimento psíquico, pois é determinante não só para a intervenção de qualquer tratamento possível, mas também na promoção de políticas públicas no País. Um exemplo recente é o aumento do número de diagnósticos de autismo e o esforço legislativo em estabelecer condições de políticas especializadas para essa população (Batista, 2013). Desse modo, esclarecer uma estratégia de diagnóstico no campo psicanalítico pode contribuir, sobremaneira, para o campo da saúde mental como intervenção de políticas públicas.

Ademais, o diagnóstico é um artifício preliminar importantíssimo para a condução do tratamento. Os efeitos da nomeação diagnóstica vêm se impondo cada vez mais no ofício do psicanalista em uma época que parece vulgarizar o trabalho diagnóstico: basta uma leitura rápida em qualquer edição do Manual Diagnóstico e Estatístico de Transtornos Mentais (DSM) (American Psychiatric Association, 2014), disponível gratuitamente na internet, para chegarmos à conclusão de que os sintomas apresentados por um sujeito podem ser facilmente reunidos em uma categoria diagnóstica e que, consequentemente, existe um tratamento medicamentoso para tal.
No campo do sofrimento psíquico, a questão da atualidade do diagnóstico da psicose provoca algumas cisões e uma não concordância em relação ao modo como ele pode ser abordado. De início, destacam-se aqui três posicionamentos diferentes que mostram como a abordagem da psicose, e o diagnóstico em si, não está plenamente decidida e que um retorno ao estudo das contribuições do estruturalismo permite-nos apontar algumas nuances. Como exemplo, encontram-se movimentos que pretendem interpretações por meio da história da psicopatologia, tal como Berlinck (2000); pela sociologia, como Melman (2009); ou ainda os que pretendem pensar a questão do diagnóstico dentro dos impasses clínicos, como Miller (2006) e Czermak (2012). Além disso, observa-se momentos na clínica em que os impasses diagnósticos suscitaram debate em relação à relevância da distinção estrutural, como a categoria borderline da década de 1970 (Hegenberg, 2000) e hoje com a hipótese das neuroses mistas (Indart, 2009) e as psicoses ordinárias (Miller, 2006).

\section{Método}

Por se tratar de um estudo teórico, admite-se que a consistência e relevância de uma pesquisa implica na articulação conceitual proposta. Dessa maneira, este artigo vale-se da orientação metodológica proposta por Canguilhem (1975/2011) como trabalho de um conceito. Essa orientação caracteriza-se por estender o conceito até seus limites, analisando os efeitos da articulação com outros conceitos com o objetivo de conferir sua fecundidade em acentuar novos problemas e explicar outros. Não é aleatoriamente que essa orientação metodológica se conjuga à lógica teórico-clínica da Psicanálise, na medida em que Freud (1915/1996), no texto As pulsões e seus destinos, salienta que um conceito só é válido enquanto é explicativo. Caso contrário, ou o abandona ou o deforma, haja vista que essa deformação do conceito se dará sempre em relação com o material empírico, que, na especificidade da Psicanálise, é a própria clínica. É essa mesma orientação que Lacan segue ao passar do Nome-do-Pai no singular para sua pluralização: os impasses da clínica, principalmente das psicoses, o leva a deformar seus conceitos considerados importantes ou fundamentais desenvolvidos sob forte diálogo com o estruturalismo na década de 1950.

Para realizar tal empreendimento, primeiramente revisitou-se as formulações dos principais autores 
do estruturalismo que tiveram influência no pensamento lacaniano, entre eles Ferdinand de Saussure, Roman Jakobson e Claude Lévi-Strauss. Posteriormente, mostrou-se como as teses estruturalistas serviram de esteio para a teorização da clínica da psicose nos anos 1950, destacando, principalmente, a questão diagnóstica dada pela estrutura e a tese da foraclusão do Nome-do-Pai. Após essa exposição, tratou-se de cotejar as vertentes que acabariam por colocar o diagnóstico estrutural sob questionamento: os "novos sintomas" e a pluralização do Nome-do-Pai. Portanto, defende-se que um retorno às contribuições do estruturalismo na clínica das psicoses permite problematizar, de maneira consistente, o alcance do diagnóstico estrutural na clínica lacaniana atualmente.

\section{O movimento estruturalista e as contribuições de Saussure, Lévi-Strauss e Jakobson}

$\mathrm{O}$ estruturalismo constituiu-se como um movimento no início do século XX na França. Deleuze (1972/2006) aponta a linguística como origem do estruturalismo, na medida em que "só há estrutura daquilo que é linguagem" (p. 272). Na mesma direção, Milner (1996) destaca a relação da linguística estrutural com a ciência moderna afirmando que a primeira é possível de se apresentar como uma matematização. Assim como a ciência pretende excluir qualquer consideração de valor e qualidade, de uma maneira que lhe é própria, o estruturalismo em linguística também seria um método de redução das qualidades sensíveis.

O estruturalismo opera a formalização de seu objeto, partindo, principalmente, de seu princípio de dessubstancialização. A linguística estrutural forneceu o rigor da formalização de seus enunciados que permitiu considerar o estruturalismo no quadro das ciências modernas. A linguística estrutural repousaria, segundo Milner (1996), sobre três teses minimalistas: em relação à teoria (uma teoria ficará mais próxima do ideal da ciência na medida em que ela impuser a um poder descritivo máximo o uso de um número mínimo de axiomas e de conceitos iniciais); em relação ao objeto (só se conhece uma língua se for imposta a ela considerar apenas as propriedades mínimas que a tomam um sistema, ou seja, só existe sistema se houver diferença); e em relação às propriedades (um elemento de um sistema tem por únicas propriedades aquelas que são determinadas pelo sistema, isto é, um elemento do sistema só subsiste como elemento numa relação de diferença).

Por sua vez, Lévi-Strauss (1958/1975) define que, para merecerem o nome de estrutura, os modelos que constituem o objeto próprio das análises estruturais devem obedecer a quatro condições: 1. Uma estrutura apresenta um caráter de sistema e consiste em elementos tais que uma modificação de qualquer um deles acarreta uma modificação de todos os demais; 2. Todos os modelos pertencem a um grupo de transformações, cada uma das quais correspondendo a um modelo da mesma família, de modo que o conjunto dessas transformações constitui um grupo de modelos; 3 . As propriedades indicadas acima permitem prever de que modo reagirá o modelo em caso de modificação de um de seus elementos; 4 . O modelo deve ser de tal modo construído que seu funcionamento possa dar conta de todos os fatos observados.

Desse modo, por estrutura entende-se um sistema de relações, representado por um modelo que descreve o funcionamento de um fenômeno. A noção de estrutura não se refere à realidade empírica, mas aos modelos construídos a partir dessa última. A estrutura não existe na realidade concreta (Motta, 2012), ou seja, a estrutura é antes o que admite ultrapassar o fenômeno, a realidade empiricamente observável, e permite explicá-lo.

$\mathrm{O}$ estruturalismo influenciou autores de diversos campos do saber, como Roland Barthes na Semiótica, Louis Althusser na Filosofia marxista e Lacan na Psicanálise, além de dialogar com outras perspectivas, como o formalismo russo. No entanto, interessa a este trabalho a chamada tríade estruturalista, cujas formulações influenciaram Lacan nos anos 1950.

O trabalho precursor de Saussure (1916/2006) em seu Curso de linguística geral merece algumas considerações importantes em relação à leitura estruturalista subsequente. Primeiramente, por se tratar de uma obra póstuma, organizada e editada em 1916 por alguns alunos de Saussure, há diversos questionamentos a respeito da identidade própria do texto. Em segundo lugar, só poderíamos situá-lo como o "precursor" do estruturalismo se considerarmos que foi ele quem desenvolveu a noção de termos dependentes em um todo que é solidário (Bez, \& Aquino, 2011), mas sabendo também que o objetivo de Saussure era investigar o funcionamento da língua como um sistema, e não como uma estrutura.

Nesse trabalho, Saussure (1916/2006) define que o objeto de estudo da linguística é a linguagem, sendo necessário não confundir o domínio da língua com a 
linguagem. $\mathrm{O}$ autor também diferencia a língua da fala ao apontar que a primeira refere-se à parte social da linguagem, que é exterior ao indivíduo e tem sua existência no contrato coletivo, a segunda é a utilização individual dessa língua. A partir dessa diferença, surgiria a linguagem como um sistema de relações em que o conhecimento do sistema permitiria o reconhecimento de todos os elementos. A língua, entendida como um sistema, é constituída por signos linguísticos que formam, cada um deles, uma unidade composta de um conceito e uma imagem acústica, chamadas de significado e significante. Tem-se, então, o signo como produto da união entre significante (imagem acústica) e significado (conceito), estando clara a relação de significação que une o significante ao significado.

Nesta formulação da teoria do signo, Saussure (1916/2006) pressupõe que a arbitrariedade se aplicaria à correspondência entre significante e significado, tornando-se um dos princípios conferidos ao signo. O significante é arbitrário em sua relação ao significado, mas não em sua relação aos outros significantes com os quais constitui o sistema de uma língua. O diálogo com a linguística estrutural de Saussure possibilitou a Lacan a elaboração de uma teoria do significante, mas não sem antes recorrer à subversão da relação de reciprocidade operada entre significante e significado na óptica saussuriana.

Importantes teóricos que se destacaram nos estudos subsequentes a Saussure foram os linguistas russos, especialmente Jakobson. Grande destaque também para os trabalhos desenvolvidos no Círculo Linguístico de Praga, fundado em 1929, no qual sobressaiu um programa de investigação e análise estruturalista.

Jakobson (1954/1995) é claro ao afirmar a importância do estudo e funcionamento da estrutura da linguagem para investigação de alguma perturbação da linguagem, como a afasia. Em seu texto-chave Dois aspectos da linguageme dois tipos de afasia, o autor apresenta duas operações fundamentais da língua: a seleção e a combinação: "falar implica a seleção de certas entidades lingüísticas e sua combinação em unidades lingüísticas de mais alto grau de complexidade" (p. 37). A seleção implica a possibilidade de substituição de um termo por outro; seleção e substituição fazem parte da mesma operação. Já a combinação é a articulação de unidades linguísticas que servem de contexto para unidades mais simples e encontram contexto numa unidade linguística mais complexa. Dessa forma, combinação e contexto são duas faces da mesma operação.
Haveria, portanto, um duplo caráter da linguagem: "os constituintes de um contexto têm um estatuto de contiguidade, enquanto num grupo de substituição os signos estão ligados entre si por diferentes graus de similaridades" (Jakobson, 1954/1995, p. 40). Nessa perspectiva, os distúrbios da fala podem afetar a capacidade tanto de combinar quanto de selecionar as unidades linguísticas.

É notório o destaque dos polos metafóricos e metonímicos em seu estudo acerca da afasia. A metáfora se produziria pelas relações de similaridade, assim como a metonímia pelas relações de contiguidade. Dito de outra forma, a atividade seletiva da linguagem é exercício de uma função metafórica e a atividade combinatória refere-se ao processo da metonímia. Jakobson (1954/1995), no fim de seu texto, assinala que esses dois processos encontram-se nas estruturas dos sonhos descritos por Freud:

A competição entre os dois procedimentos, metonímico e metafórico, se torna manifesta em todo processo simbólico, quer seja subjetivo, quer seja social. Eis por que numa investigação da estrutura dos sonhos, a questão decisiva é saber se os símbolos e as sequências temporais usadas se baseiam na contiguidade ("transferência" metonímica e "condensação" sinedóquica de Freud) ou na similaridade ("identificação" e "simbolismos" freudianos) (p. 60).

Na lógica jakobsoniana, toda significação linguística é diferencial. A partir da constatação de que a estrutura é como uma rede de relações, então seria preciso no mínimo dois elementos para haver relação. Por meio de uma relação diferencial, os elementos se determinariam mutuamente pela lógica dessas relações. Jakobson também trabalhou em íntima colaboração com Lévi-Strauss e o campo de antropologia estrutural. A referência da linguística estrutural serviu de base às análises antropológicas de Lévi-Strauss; foi ele quem aproximou a Psicanálise e o estruturalismo linguístico. Segundo Motta (2012), coube a Lévi-Strauss o mérito de ter sido o primeiro a teorizar de forma sistemática a noção de estrutura - apoiada na noção de constructus linguístico - além de sua influência nos anos 1950 e meados dos 1960 ter assegurado ao estruturalismo francês uma posição privilegiada no âmbito da circulação internacional das ideias. 
Em seu célebre estudo de 1949 sobre As estruturas elementares do parentesco, o autor francês investiga os mecanismos que orientam as regras normativas de diferentes sistemas de parentesco primitivo. A proibição do incesto, por exemplo, poderia ser vista como uma necessidade estrutural à passagem da natureza para a cultura. Lévi-Strauss (1949/1982) buscou no estudo da Fonologia um modelo para a análise das relações de parentesco. Para a Fonologia, os fonemas são elementos de um sistema que privilegia as relações internas entre os termos em detrimento de suas propriedades. Assim como os fonemas, os termos de parentesco são elementos que só adquirem significação sob a condição de se integrarem em sistemas:

O lingüista extrai das palavras a realidade fonética do fonema e deste, a realidade lógica dos elementos diferenciais. E, tendo reconhecido em várias línguas a presença dos mesmos fonemas ou a utilização dos mesmos pares de oposição, não compara seres individualmente distintos: é o mesmo fonema, o mesmo elemento, que lhe garante nesse novo plano a identidade profunda de objetos empiricamente diferentes (p. 35).

O diálogo lévi-straussiano com a Fonologia é evidente. Desse modo, conforme lido em As estruturas elementares do parentesco, não é considerável que um grupo tenha consciência das relações de troca. Assim como os princípios que regem a combinação dos fonemas numa língua, os princípios elementares que regulam a troca não precisam se revelar à consciência daqueles que o empregam, segundo Motta (2012).

Também as formulações sobre o simbólico e a estrutura do mito, a partir da linguística estrutural e, principalmente, das formulações de Saussure, colocam Lévi-Strauss no cerne da discussão estruturalista. Conforme os princípios de uma linguística estrutural, os mitos só possuiriam sentido a partir da ordenação e composição de seus elementos, e não resultante dos elementos isolados em si. Como o mito pertence à ordem da linguagem, os elementos que são próprios a ele devem ser pensados como unidades constitutivas (Lévi-Strauss, 1958/1975).

Viveiros de Castro (2015) realizou uma investigação a respeito da contribuição de Lévi-Strauss na óptica estruturalista: "a grande questão que se abre hoje, no processo de reavaliação da herança intelectual de Lévi-Staruss, é a de decidir se o estruturalismo é inter- namente contínuo ou descontínuo" (p. 234). O autor defende que na obra lévi-straussiana podem ser encontradas dois projetos de estruturalismo em tensão criativa entre si: o primeiro projeto referindo-se à primeira fase de sua obra, representada por As estruturas elementares do parentesco, e o segundo, já na fase tardia de sua obra, aproximando-se mais das características pós-estruturalista e representado pelas Mitológicas e a três monografias subsequentes, A via das máscaras, A oleira ciumenta e História de Lince. $\mathrm{O}$ autor ainda destaca que a própria noção de estrutura ganha conotações distintas nesses "dois estruturalismos": a estrutura como "combinatória gramatical fechada e como multiplicidade diferencial aberta" (p. 246), respectivamente.

Por meio da obra de Lévi-Strauss, Lacan tomou conhecimento de Saussure e trabalhou diretamente com seu Curso de linguística geral. O estruturalismo foi o recurso articulado por Lacan no início dos anos 1950 em reação ao desvio que a Psicanálise vivia nos primórdios de seu ensino: alguns pós-freudianos acabaram por se desviar dos próprios princípios freudianos, confundindo-os com os termos de uma Psicologia evolutiva. Com isso, afastavam seus princípios dos fundamentos de Freud. Ao propor reler Freud a partir do estruturalismo, Lacan (1957/1998) reconduz a experiência fundamental da Psicanálise à linguagem: "é toda a estrutura da linguagem que a experiência analítica descobre no inconsciente” (p. 498).

\section{Lacan e o estruturalismo}

$\mathrm{O}$ aforismo o inconsciente é estruturado como uma linguagem marca o momento em que Lacan dialoga com o paradigma estruturalista e daí extrai sua proposta de releitura da Psicanálise. A respeito da apropriação lacaniana dos princípios estruturalistas, há alguns textos importantes que evidenciam o trabalho de significantização do primeiro ensino de Lacan.

Função e campo da fala e da linguagem em psicanálise ou Discurso de Roma, como também é conhecido, é o título de um relatório produzido por Lacan (1953/1998), em 1953. Esse texto destaca-se pela sua proposta até então audaciosa, haja vista o contexto da ortodoxia da Sociedade Psicanalítica de Paris, à qual Lacan estava inicialmente vinculado. Sua tese é clara: os princípios teóricos e práticos da Psicanálise devem se reconhecer na estrutura da linguagem. Não só o anteparo teórico do estruturalismo pode ser reconhecido nesse texto, especialmente a antropologia estrutural de Lévi-Strauss, mas também é nítido o esforço 
em reconduzir a experiência psicanalítica aos determinantes da linguagem, no qual é destacado o lugar da ordem simbólica como dimensão última na constituição do sujeito: o homem fala porque o símbolo o fez homem, ou seja, é na dimensão da linguagem simbólica que o sujeito se vê constituído.

O homem já nasce imerso num sistema simbólico que o sobredetermina (Lacan, 1953/1998). Na medida em que a linguagem simbólica insere-o na cultura, estabelece também uma nova relação com a realidade, baseada na mediação do símbolo entendido como significantes do pacto que constituem como significado.

Outro texto característico desse momento fecundo de apropriação dos princípios estruturalistas é A instância da letra no inconsciente ou a razão desde Freud, de 1957 (Lacan, 1957/1998). É notório também que o diálogo com a linguística estrutural não ocorreu sem a subversão de certas formulações capitais, como pode ser visto nesse texto. Em A instância da letra, é abordado, a partir das noções de metáfora e metonímia da linguística estrutural, como o significante possui formas particulares de articular-se. Lacan (1957/1998) lança mão da formalização de um algoritmo que sustenta a subversão da relação dos conceitos de significante e significado em Saussure.

Como mostrado anteriormente, para Saussure (1916/2006), o significante e o significado, como duas instâncias, tem como produto de sua articulação o signo. Compreende-se uma subordinação do significante à ordem do significado. No entanto, Lacan (1957/1998) afirma que essa distinção primordial está "muito além do debate relativo à arbitrariedade do signo" (p. 500) e propõe o algoritmo $S / s$, no qual se lê: "significante sobre significado, correspondendo-o sobre a barra que separa as duas etapas” (p. 500).

Nessa formalização está inscrita a primazia do significante, uma vez que este não tem a função de representar, por sua existência, o significado. Assim, nenhuma significação se sustenta a não ser pela remissão a outra significação. Entende-se que o que faz parte da própria estrutura do significante é a articulação com outros significantes - daí a noção de cadeia que Lacan (1957/ 1998) fornece a seguinte ilustração: "anéis cujo colar se fecha no anel de um outro colar feito de anéis" (p. 505) - e que tal articulação existe, na medida em que os significantes podem ser reduzidos a puros elementos diferenciais.

Em relação à metonímia, Lacan (1957/1998) diz que é a função propriamente significante na linguagem: é na palavra em palavra dessa conexão que se apoia a metonímia. Já a fórmula da metáfora se dá em uma palavra por outra palavra. Trata-se de uma substituição significante, produzindo seu efeito "entre dois significantes dos quais um substituiu o outro, assumindo seu lugar na cadeia significante, enquanto o significante oculto permanece presente em sua conexão (metonímia) com o resto da cadeia" (p. 510). À formulação dos conceitos de metáforas e metonímia, Lacan (1957/1998) referencia o trabalho de Jakobson "onde um psicanalista encontra a todo instante com que estruturar sua experiência” (p. 509).

É notável o papel da linguística estrutural na formalização da experiência psicanalítica nesse primeiro momento caracterizado como um retorno a Freud. O pensamento estruturalista forneceu as bases para que Lacan pudesse conjecturar uma teoria da constituição do sujeito estruturado pelo simbólico e efeito da cadeia significante - um significante é aquilo que representa um sujeito para outro significante. Sob essas coordenadas foi possível pensar a psicose em termos de significantes e sustentar sua estrutura a partir da foraclusão de um significante primordial: o Nome-do-Pai.

\section{A clínica da psicose na década de 1950 - a foraclusão do Nome-do-Pai}

A partir do esteio estruturalista, tornou-se tarefa possível conceituar o mecanismo específico da estrutura psicótica, tendo como base um conceito importante, a saber, o Nome-do-Pai. Nessa direção, Sales (2007) arremata:

[...] o que o estruturalismo fornece a Lacan, em especial no desenvolvimento de seu terceiro seminário, é uma teoria formalizada da determinação diferencial da psicose encaixada numa teria mais geral da constituição do sujeito. A colocação da psicose sob a dependência do modo de operação de um dos elementos do Édipo - o Nome-do-Pai - faz com que sua diferença frente à neurose seja de ordem estrutural (p. 216).

Observa-se no ensino lacaniano que o trabalho de conceituação do Nome-do-Pai é fecundo quando pensado em um campo cujos efeitos desse significante estariam ausentes: a psicose. É o que se pode extrair do Seminário 3 - As Psicoses, proferido entre os anos de 1955 e 1956. Nesse seminário, Lacan (1955/2008) se ocupa em destrinchar os efeitos da não inscrição 
de um significante primordial. Como exemplo, o autor trabalha a ilustração da estrada principal, aquela que permite chegar a um determinado ponto, para dizer que o significante ser pai constituiria essa via principal. Na neurose haveria essa via principal, ao passo que na psicose ela não estaria lá. Assim, as alucinações seriam como as placas à beira da estrada que orientariam o deslocamento de um ponto ao outro: "ali onde o significante não funciona, isso me põe a falar sozinho à beira da estrada principal. Ali onde não há estrada, as palavras escritas aparecem nos letreiros" (p. 340).

No entanto, será em De uma questão preliminar a todo tratamento possivel da psicose, texto de 1958, que Lacan (1958/1998) fornecerá um estatuto lógico à falta de um significante primordial trabalhado anteriormente no Seminário 3: a foraclusão do Nome-do-Pai. Nesse texto, encontram-se formulações teórico-clínicas que situam a psicose no campo próprio da Psicanálise, como assinalou Lacan - o campo da fala e a função da linguagem. Na psicose, o sujeito se posicionaria em função de dois parâmetros estruturais: a foraclusão do Nome-do-Pai e a ausência de significação fálica.

O Nome-do-Pai tem um estatuto fundamental na teoria lacaniana da psicose na década de 1950. Ao indicar que a significação fálica "só é evocada pelo o que chamamos de metáfora, precisamente a metáfora paterna" (p. 561), Lacan (1958/1998) conceitua como o significante Nome-do-Pai o produtor dessa significação sob a função fálica. A função do pai é ser um substituto do primeiro significante introduzido na significação, a saber, o significante materno.

O pai, a mãe, a criança e o falo são os elementos em jogo nessa operação. A metáfora paterna é a operação que permite ao sujeito inscrever-se na ordem fálica, inscrevendo no Outro o falo como significante (do desejo). A metáfora paterna e a maneira como cada um articula esses elementos definirão o modo de estruturação do sujeito: neurose, psicose ou perversão. No caso da estrutura neurótica, o resultado desse processo de substituição significante é a emergência de uma nova significação: a significação fálica. É essa significação que permite ao sujeito se orientar na ordem simbólica, implicando em não mais ser o falo, mas sim se posicionar em relação a ele na partilha dos sexos.

Na psicose, Lacan (1958/1998) estabelece uma "circunstância da posição subjetiva em que o apelo do Nome-do-Pai corresponda [...] à carência do próprio significante" (p. 563). Extraído de Freud, o termo Verwerfung é lido por Lacan como a foraclusão desse significante sustentador da ordem simbólica, o que provocará "um furo correspondente no lugar da significação" (p. 564) pela carência do efeito metafórico. A não operação da metáfora paterna impossibilita a inscrição substitutiva do pai como significante no lugar da mãe.

Se o Nome-do-Pai inaugura a simbolização para o sujeito, a foraclusão deste na psicose corresponde à não inclusão da castração simbólica, ou seja, o significante do Nome-do-Pai no ponto de basta que produziria, por retroação significante, a significação fálica. Analisando o famoso caso Schreber, Lacan (1958/1998) chega à afirmação de que não há nada nos fenômenos da psicose que estaria fora da estrutura da linguagem. É nessa direção que os fenômenos da psicose são lidos como fenômenos de mensagem e código e analisados como efeito de alterações na estruturação significante nessas duas ordens de fenômenos.

Os fenômenos de mensagem dizem respeito ao momento em que a frase é interrompida justamente no ponto em que surgiria a significação. Os fenômenos de código referem-se às locuções neológicas em que o "próprio significante é o objeto da comunicação" (Lacan, 1958/1988, p. 544), assinalando a separação radical entre significante e significado. Esses fenômenos só fazem sentido se referidos à foraclusão do Nome-do-Pai. A clínica lacaniana das psicoses dos anos 1950 também destaca o desencadeamento, noção ricamente conceituada nesse primeiro momento. O desencadeamento refere-se ao momento em que o psicótico é chamado a responder de um lugar referenciado pelo significante primordial, o que corresponde à condição estrutural própria da psicose: a foraclusão do Nome-do-Pai.

Observa-se que o diálogo com as formulações estruturalistas proporcionaram uma abordagem fecunda da clínica da psicose orientada pela centralidade de um significante, o Nome-do-Pai, e a relação estruturante do significante e o sujeito. O Nome-do-Pai, em sua ausência ou presença, determinaria a distinção das estruturas. No entanto, demandas contemporâneas problematizam a respeito da importância da hipótese estrutural e, de um modo geral, se a herança estruturalista estaria ultrapassada. Atualmente, vários questionamentos direcionam-se aos casos clínicos que teriam o estatuto de denunciar os limites da concepção estrutural pautada na distinção entre as estruturas; interrogar sobre a validade da distinção clássica neurose-psicose (Tironi, 2010; Laender, 2009) e as categorias clínicas ordenadas a partir da presença ou 
da ausência do significante do Nome-do-Pai (Maron, 2009), promovendo um mais além da perspectiva estritamente estruturalista (Santos, 2010).

\section{O diagnóstico estrutural sob questionamento: os "novos sintomas" e a pluralização do Nome-do-Pai}

No tocante à clínica de orientação lacaniana, questões relativas ao diagnóstico sempre estiveram cercadas por várias interrogações, seja pela associação ao discurso psiquiátrico, caracterizado por um diagnóstico supostamente objetivo, seja pelos impasses de pensá-lo em relação à radicalidade do sujeito, tomado como "inclassificável”. Miller (1997) já acentuou que "é compreensível que o primeiro movimento de um 'lacaniano' possa ser o de rejeitar a idéia de diagnóstico" (p. 230).

O estabelecimento de um diagnóstico na clínica não é de modo algum inócuo. Para o sujeito, abre-se logo um leque de opções para o tratamento; para o campo da saúde pública, revelam-se propostas de intervenção para uma população que agora necessita de uma política específica. Para o campo psicanalítico, o diagnóstico é constituído em nível do sujeito. Como Milner (1983/2006) elucida, de forma pertinente, é permitido à psiquiatria a construção de nosografias, podendo até enumerar sintomas como propriedades caracterizadoras; já a Psicanálise deve reconhecer que se trata aí de semblantes, pois algo para além subsiste e não está esgotado na classe representável, ou seja, o próprio sujeito.

O diagnóstico estrutural, herdeiro do diagnóstico diferencial proposto por Freud desde o início de suas teorizacões, aparece com Lacan em um momento específico de seu ensino com a proposta de um retorno a Freud a partir do estruturalismo e a formalização das estruturas clínicas, diferenciando-se, sobretudo, de um diagnóstico baseado somente na denominação sintomática ao apontar as três grandes estruturas clínicas pensadas segundo três modalidades de resposta: o recalque na neurose, o desmentido na perversão e a foraclusão na psicose.

O Nome-do-Pai é o ponto de partida de Lacan para discutir a diferença estrutural. As coordenadas diagnósticas da clínica da década de 1950 orientavam-se em referência a esse operador lógico, portanto, é válido dizer que o diagnóstico em Psicanálise teria como baliza o Nome-do-Pai. Além de fornecer uma delimitação lógica para o campo da psicose, a foraclusão do Nome-do-Pai constituiu-se como a referência para o estabelecimento do diagnóstico da estrutura psicótica, uma vez que os fenômenos elementares tornaram-se os traços fundamentais para o diagnóstico da psicose. Essa foi uma das grandes contribuições do estruturalismo à teoria lacaniana da psicose nos anos 1950 .

No ensino lacaniano, as primeiras conceituações do Nome-do-Pai o definem como um suporte da função simbólica, um significante inerente ao campo do Outro, capaz de operar como lei que ordena o conjunto dos significantes: é o Outro no Outro, diz Lacan (1958/1999) no Seminário 5. Portador de uma interdição sobre o gozo primordial, o Nome-do-Pai é o ponto de basta que detém o deslize da cadeia dos significantes, garantindo a estruturação da ordem simbólica. Segundo Feliciotti e Viganò (2007), "esse é um conceito que se separa da fenomenologia observável e, portanto, coloca as dificuldades como instrumento para o diagnóstico" (p. 23).

Entretanto, o conceito de Nome-do-Pai sofreu uma reformulação no ensino lacaniano, o que ficou conhecido como o movimento de pluralização do Nome-do-Pai: há um caminho entre "o pai no singular como Nome-do-Pai, sustentação da ordem simbólica e portador da interdição, até a sua função de sinthoma" (Zenoni, 2007, p. 15). Os Nomes-do-Pai seriam tema do décimo primeiro seminário de Lacan, em 1963. Porém, sua exclusão do quadro de didatas da IPA forçou-o a não dar continuidade ao seu seminário. Na única lição existente do seminário os Nomes-do-Pai, é possível encontrar em que direção Lacan (1963/2005) pretendia seguir no "progresso de uma noção" (p. 58).

Há duas elaborações teóricas que auxiliam a entender como se deu a passagem para a pluralização do Nome-do-Pai: o matema $S(X)$ e o objeto $a$. Na construção final do grafo do desejo, Lacan (1960/1998) escreve que no conjunto do Outro (A), definido como o tesouro dos significantes, haveria uma falta, a qual aponta para um Outro desejante. A introdução de uma barra sobre o Outro, representado pelo matema $S(\AA)$, marcou "um giro decisivo" (Maleval, 2002, p. 88) na concepção do Nome-do-Pai ao revelar uma hiância estrutural no campo do Outro. Essa falha estrutural no conjunto dos significantes desvela desde já uma deformação na definição do Nome-do-Pai como operador simbólico.

Ao lado dessa mudança no estatuto do Outro, indicando sua incompletude com o matema $S(X)$, outro ponto presente no ensino de Lacan constituiu um campo do possível para o movimento de pluralização dos Nomes-do-Pai: a formalização do objeto $a$. 
As formulações sobre o objeto $a$ presente no Seminário 10 - A Angústia e a mudança que imporá ao estatuto do Nome-do-Pai também pode ser encontrada textualmente em Lacan (1963/2005) em sua única lição do Seminário Nomes-do-Pai. Para elucidar a passagem dos Nomes-do-Pai, tema do então Seminário, Lacan apoia-se em seus ensinos passados para assinalar as balizas que fundamentam os delineamentos da lógica do plural do nome:

O fato de remeter a meus seminários passados aqueles que queiram tentar ver em que direção eu pretendia prosseguir meu discurso mostra-lhes que há uma direção já muito avançada em sua estrutura que poderia ter me permitido dar este ano o passo seguinte. Esse passo seguinte encadeia-se ao meu seminário sobre a angústia (p. 58).

Está claro que as formulações sobre o objeto $a$ na relação com a angústia como emergência do desejo do Outro devem estar presentes na investigação de como Lacan pretendia abordar a pluralização do Nome-do-Pai. Sem pretender abordar exaustivamente o assunto, adianta-se que o objeto $a$ imporá deformação no conceito do Nome-do-Pai em seu aspecto relativo ao gozo, além de possibilitar uma nova abordagem da psicose na chamada clínica do gozo.

O Nome-do-Pai, enunciado no plural, é deslocado de seu lugar de exceção, abrindo, assim, vias para se pensar em outras formas de fazer suplência à carência paterna. A pluralização do Nome-do-Pai testemunha outras maneiras de se haver com uma falta no campo do Outro que não se restringe à psicose, mas que se inscreve para todos. Será seguindo esse horizonte que se encontra a formalização da noção de sinthoma. Se em um primeiro momento Lacan acentua o significante no simbólico a partir do Nome-do-Pai, como um Outro no Outro, posteriormente se constata que no conjunto dos significantes alguma coisa ficaria de fora, podendo afirmar que não há um Outro do Outro.

A pluralização do Nome-do-Pai atesta para a modificação de seu lugar de exceção, ocupando um lugar de significante primordial no conjunto do Outro, para uma das possibilidades de localização do gozo e amarrações sinthomáticas. E é justamente a psicose responsável por mostrar que haveria várias formas de ponto de basta que não passam pela sustentação desse significante, como foi demonstrado por Lacan (1975/2007) no Seminário 23 e a função da escrita em Joyce.
O que vai sendo cada vez mais investigado por Lacan é a relação do sujeito com o Real, Simbólico e o Imaginário, relação essa trabalhada na topologia dos nós. Se no Seminário RSI articula-se o nó a três, será no Seminário 23 que Lacan (1975/2007) estabelece que o enodamento se dá por meio de um quarto elemento "sem o qual nada é possível no nó do simbólico, do imaginário e do real" (p. 28) e apresenta a noção de sinthoma. O sinthoma passa a atuar, assim como o Nome-do-Pai, como um modo de amarração possível dos três registros.

O Nome-do-Pai, tornando-se múltiplo, também revela que cada sujeito pode servir-se dele a sua maneira, evidenciando a singularidade da invenção do sujeito em seu sintoma: "o Nome-do-Pai parece sofrer um esvaziamento de estatuto: de figura central para a distinção estrutural ele acaba virando um tipo de amarração entre muitos outros possíveis" (Lustoza, \& Calazans, 2010, p. 564). Observa-se que o percurso lacaniano de transmissão desse conceito passa por rupturas e descontinuidades, mas Lacan mantém o Nome-do-Pai como ferramenta teórico-clínica fundamental em sua teoria.

É inegável que tais mudanças no conceito de Nome-do-Pai também apresentaram ressonâncias no campo diagnóstico, pois, como foi destacado anteriormente, o Nome-do-Pai constituiu-se como o parâmetro inicial para estabelecer a distinção entre as estruturas clínicas: "Do lado do binário clássico neurose-psicose, temos um traço distintivo pertinente: Nome-do-Pai, sim ou não" (Miller, 1997, p. 106). As reformulações advindas com a pluralização do Nome-do-Pai firmaram limites ao lugar universal atribuído ao conceito. Desse modo, observa-se que a referência à ausência/presença do Nome-do-Pai para o diagnóstico foi sendo deslocada para a ideia da localização de um ponto de basta no atamento dos três registros. Na clínica orientada pela topologia nodal, esse ponto de basta produziria uma operação de enodamento entre os registros, revelando que cada caso terá seu modo particular de amarração.

Somando-se ao movimento de pluralização do Nome-do-Pai, outro aspecto legitima o questionamento do diagnóstico apoiado na distinção estrutural. A clínica evidencia que as manifestações sintomáticas encontradas atualmente parecem desconsiderar os parâmetros clássicos da estrutura neurótica e psicótica. Será que dentro desse movimento o diagnóstico estrutural estaria desacreditado e a herança estruturalista ultrapassada? 
Os casos ditos "inclassificáveis" relacionados à psicose comportariam estabilizações que não reportariam ao desencadeamento que revelam a fenomenologia típica da psicose: delírios, alucinações e transtornos de linguagem. Henriques e Birman (2003) apontam para os aspectos fenomênicos discretos das novas formas de apresentação da psicose em comparação com os quadros extraordinários e ao desencadeamento ruidoso. Esses índices que apontariam para o diagnóstico preciso da psicose se encontram mais fluidos, configurando em casos que ficariam no limbo diagnóstico.

As discussões sobre a noção de psicose ordinária entram nesse contexto. $\mathrm{O}$ termo psicose ordinária foi cunhado por Miller (2006) durante um ciclo de conversações realizado pelo Campo Freudiano na década de 1990. Essas conversações giravam em torno das discussões de casos clínicos que se apresentavam como desafiadores no estabelecimento de um diagnóstico; os "inclassificáveis" da teoria psicanalítica. Casos em que o diagnóstico diferencial, ou seja, pautado na distinção das estruturas entre neurose e psicose, não estava claro devido à singularidade sintomática. A psicose ordinária se diferencia da psicose dita extraordinária por não conter os traços paradigmáticos da loucura, como o caso Schreber, que demonstram de forma exuberante os transtornos de linguagem e de pensamento e não deixam nenhuma margem de dúvida quanto ao seu diagnóstico de psicose.

Esses questionamentos seriam suficientes para desacreditar na orientação fornecida pela estrutura no estabelecimento de um diagnóstico e na teoria clássica da psicose - desenvolvida sob influência estruturalista? É certo que as últimas formulações de Lacan sobre a clínica da psicose avançaram muito no sentido de abarcar as diversas amarrações dos três registros que possibilitam que o sujeito psicótico não passe pelo desencadeamento.

Para Tendlarz (2009), a manutenção do par neurose-psicose se torna cada vez mais importante para orientar o diagnóstico numa época em que há a presença de uma fenomenologia das neuroses devido a identificação de ideais débeis, fazendo com que a referência a atos (acting-out e passagem ao ato) se tornem preponderantes em alguns sujeitos. Brodsky (2011), por sua vez, fala da necessidade da localização da estrutura clínica em cenários como esses: "nada elimina que a localização da estrutura constitua uma das principais apostas das entrevistas preliminares. Seja qual for nossa perspectiva nesse terreno, as entrevistas preliminares devem permitir uma localização da estrutura" (p. 15).

Mesmo diante da modalização do Nome-do-Pai referente à constatação da falha estrutural no Outro, permitindo a inscrição da pluralidade desse nome, e sua equiparação ao sinthoma como modos de amarração, além do surgimento de novos sintomas, aposta-se na importância da hipótese estrutural no sentido de sustentar a diferença que especifica a psicose em relação à neurose. Vieira (2010) acrescenta: "o diagnóstico mobiliza. Para nós, o mais importante deles foi e continua sendo o dito 'estrutural', entre psicose, neurose e perversão" (p. 123).

\section{Considerações finais}

Após o percurso desenvolvido, o que se pode ver que permanece do legado estruturalista na teorização lacaniana? Como dito anteriormente, o aporte estruturalista forneceu as bases para Lacan conceituar uma teoria da constituição do sujeito estruturado pelo significante no campo da linguagem e, partindo desse quadro geral, articular a especificidade da psicose e estabelecer uma hipótese causal de sua estrutura: a foraclusão do Nome-do-Pai. Não obstante, extrai-se a importância do diagnóstico apoiado na distinção estrutural.

Pode-se também contar com Miller (1994) para responder a essa questão. No texto S'truc dure, Miller (1994) define o estruturalismo com base no que ele não seria - uma doutrina substancialista - e demonstra que Lacan parte dessa concepção antissubstancialista para excluir qualquer proposição que forneça ao sujeito algum tipo de substância ou qualidade intrínseca que o defina.

O antissubstancialismo pode ser lido em Saussure (1916/2006) ao assinalar que as combinações linguísticas produzem "uma forma, não uma substância" (p. 131) e que a língua é um sistema no qual "só existem diferenças” (p. 139). Jakobson (1995) radicaliza essa concepção ao considerar que tudo pode ser formulado a partir de uma mínima oposição de dois: dois fonemas que compõem um par de opostos. Desse binarismo estrutural, podemos ler em Lacan (1960/1998) que o mínimo de significantes é dois e que como S1-S2 mantêm entre si relações de oposição, o sujeito só surge aí como efeito de significação, já que um significante não pode significar a si mesmo. Essa é uma herança direta da hipótese estruturalista no ensino de Lacan. 
É evidente que a teoria da constituição do sujeito determinado pelo efeito do significante proporcionou as bases para pensar a psicose na relação com a linguagem, circunscrevendo a questão preliminar para o tratamento possível da psicose. A esse propósito, Lacan (1966/1998) é claro ao afirmar em A ciência e a verdade que o "estruturalismo permitiu elaborar logicamente [...] o sujeito, e o sujeito tomado numa divisão constitutiva" (p. 870). Desse modo, assinala-se como a proposta estruturalista influenciou a formalização de uma categoria fundamental no ensino lacaniano: o conceito de sujeito.

As formulações teórico-clínicas da psicose nos anos 1950 deixam claro o diálogo lacaniano com o aporte da linguística estruturalista, principalmente com as noções de metáfora/metonímia, significante e linguagem. Essa clínica da psicose organiza-se em torno da centralidade de um conceito: o Nome-do-Pai. Ele é o elemento forjado inicialmente por Lacan para pensar a diferença estrutural, sua presença ou ausência definiriam uma estrutura neurótica, perversa ou psicótica. Por essa razão, o Nome-do-Pai também seria um índice importantíssimo nas coordenadas diagnósticas, sobretudo para se pensar em um diagnóstico estrutural.

Entretanto, o laço social contemporâneo emerge questões que apontam para uma discussão a respeito da atualidade e alcance do diagnóstico estrutural e o questionamento que sua orientação vem sofrendo pelo aparecimento de "novos sintomas", sintomas esses que seriam resistentes a uma diferenciação estrutural. Ao lado desses questionamentos que pululam da clínica, há de se pontuar também a mudança teórica imputada ao estatuto do Nome-do-Pai nas últimas formalizações lacanianas, que deixaria de contar com o lugar de centralidade outrora ocupado nos anos 1950.
Este artigo propõe como direção possível que, apesar desses questionamentos, tanto teóricos quanto clínicos, a orientação fornecida pela estrutura na construção do diagnóstico não deve ser desacreditada. Considera-se apressado declarar a descrença no diagnóstico estrutural, principalmente quando colocado em relevo a questão da psicose e a tese da foraclusão do Nome-do-Pai como determinante de sua estrutura. Vascheto e Yegatti (2008) apontam a importância da localização estrutural, pois a estrutura permite ver como se arranja o sujeito, tendo incidências sobre a condução do tratamento.

Não é um propósito também confrontar as chamadas primeira e segunda clínica lacaniana em termos de qual abordagem seria mais válida no tocante ao diagnóstico e tratamento da psicose. Se, por um lado, o aparato teórico do estruturalismo nos anos 1950 serviu como base para Lacan estabelecer o estatuto do sujeito na dependência do significante e daí extrair consequências clínicas importantes para o tratamento da psicose, por outro lado, referido cada vez mais à formalização da topologia dos nós no fim de seu ensino, Lacan pôde evidenciar a riqueza da variabilidade das saídas sinthomáticas do psicótico quando da falta do Nome-do-Pai.

Assinala-se a relevância da noção de estrutura para pensar o diagnóstico na clínica da psicose. No entanto, ainda assim é necessário reconhecer que existem fenômenos e quadros clínicos atuais que podem desafiar o legado estruturalista, especialmente a distinção estrutural, como a melancolia e a depressão, as toxicomanias, a ideia de uma perversão social, entre outros que não abordamos neste artigo, mas que poderão ser cotejadas numa pesquisa futura a partir das direções aqui elencadas. Possibilidades de estudos futuros incluem a investigação de casos clínicos cuja sintomatologia desafia a lógica estrutural.

\section{Referências}

American Psychiatric Association. (2014). Manual diagnóstico e estatístico de transtornos mentais 5. Porto Alegre, RS: Artes Médicas.

Batista, C. (2013). Autismo, política e instituição. Trivium, 5(1), 46- 63. Recuperado de http://pepsic.bvsalud.org/ scielo.php?script=sci_arttext\&pid=S2176-48912013000100007

Berlinck, M. (2000). Psicopatologia fundamental. São Paulo, SP: Escuta.

Bez, A., \& Aquino, C. (2011). Saussure e o estruturalismo: retomando alguns pontos fundamentais da teoria saussuriana. Cadernos do IL, (42), 5-17. Recuperado de http://www.seer.ufrgs.br/index.php/cadernosdoil/article/ view/26000/15222

Brodsky, G. (2011). Loucuras discretas. Belo Horizonte, MG: Scriptum. 
Canguilhem, G. (2011). Dialética e filosofia do não em Gaston Bachelard. In H. Bergson, \& G. Canguilhem, Estudos de história e de filosofia das ciências. Rio de Janeiro, RJ: Forense Universitária. (Originalmente publicado em 1975).

Czermak, M. (2012). Patronimias. Rio de Janeiro, RJ: Tempo Psicanalítico.

Deleuze, G. (2006). Em que se pode reconhecer o estruturalismo? In G. Deleuze. A ilha deserta e outros textos (pp. 221- 247). São Paulo, SP: Iluminuras. (Originalmente publicado em 1972).

Feliciotti, P. \&Viganò, C. (2007). Pode-se fazer um diagnóstico de pré-psicose?: uma questão preliminar ao diagnóstico de estrutura. Mental, 5(8), 15-38. Recuperado de http://pepsic.bvsalud.org/scielo.php?script=sci_arttext\&pid=S1679-44272007000100002\&lng=es\&nrm=is\&tlng=pt

Freud, S. (1996). As pulsões e seus destinos. In J. Strachey (Ed., Trad.). Edição standard das Obras psicológicas completas de Sigmund Freud (v. 14, pp. 115-144). Rio de Janeiro, RJ: Imago. (Originalmente publicado em 1915).

Hegenberg, M. (2000). Borderline. São Paulo, SP: Casa do Psicólogo.

Henriques, R. S. P., \& Birman J. (2003). Elementos para uma apreensão clínica da psicose ordinária (Jean-Calude Maleval, 2003). Clínica \& Cultura, 3(1), 105-169. Recuperado de http://www.seer.ufs.br/index.php/clinicaecultura/article/view/2841

Indart, J. (2009). Entre neurosis y psicosis: fenómenos mixtos en la clinica psicoanalitica actual. Buenos Aires: Grama.

Jakobson, R. (1995). Lingüística e comunicação. São Paulo, SP: Cultrix. (Originalmente publicado em 1954).

Lacan, J. (1998). A ciência e a verdade. In J. Lacan, Escritos (pp. 869-892). Rio de Janeiro, RJ: Jorge Zahar. (Originalmente publicado em 1966).

Lacan, J. (1998). A instância da letra no inconsciente ou a razão desde Freud. In J. Lacan, Escritos (pp. 496-533). Rio de Janeiro, RJ: Jorge Zahar. (Originalmente publicado em 1957).

Lacan, J. (1999). As formações do inconsciente (O seminário, Vol 5). Rio de Janeiro, RJ: Jorge Zahar. (Originalmente publicado em 1958).

Lacan, J. (2008). As psicoses (O seminário, Vol 3). Rio de Janeiro, RJ: Jorge Zahar. (Originalmente publicado em 1955).

Lacan, J. (1998). De uma questão preliminar a todo tratamento possível da psicose. In J. Lacan, Escritos (pp. 537-590). Rio de Janeiro, RJ: Jorge Zahar. (Originalmente publicado em 1958).

Lacan, J. (1998). Função e campo da fala e da linguagem em psicanálise. In J. Lacan, Escritos (pp. 238-324). Rio de Janeiro, RJ: Jorge Zahar. (Originalmente publicado em 1953).

Lacan, J. (2005). Nomes-do-pai. Rio de Janeiro, RJ: Jorge Zahar. (Originalmente publicado em 1963).

Lacan, J. (2007). O sinthoma (O seminário, Vol. 23). Rio de Janeiro, RJ: Jorge Zahar. (Originalmente publicado em 1975).

Lacan, J. (1998). Subversão do sujeito e dialética do desejo no inconsciente freudiano. In J. Lacan, Escritos (pp. 807-842). Rio de Janeiro, RJ: Jorge Zahar. (Originalmente publicado em 1960).

Laender, N. (2009). Um caso clínico em questão: neurose ou psicose? Estudos de Psicanálise, (32), 129-140. Recuperado de http:/ / www.cbp.org.br/neuroseoupsicose.pdf

Lévi-Strauss, C. (1975). Antropologia estrutural. Rio de Janeiro, RJ: Tempo Brasileiro. (Originalmente publicado em 1958).

Lévi-Strauss, C. (1982). As estruturas elementares do parentesco. Petrópolis, RJ: Vozes. (Originalmente publicado em 1949).

Lustoza, R., \& Calazans, R. (2010). Alcance e valor do nome-do-pai atualmente: algumas considerações. Psicologia em Estudo, 15(3), 557-565. https://dx.doi.org/10.1590/S1413-73722010000300013

Maleval, J-C. (2002). La forclusión del Nombre del Padre: el concepto y su clínica. Buenos Aires: Paidós.

Maron, G. (2009). La psicosis ordinaria como diagnostico psicoanalítico. Virtualia, 8(19), 3-6. Recuperado de http://virtualia.eol.org.ar/019/template.asp?variedades/maron.html

Melman, C. (2009). La nouvelle economie psychique: la façon de penser e de jouir ajourd'hui. Toulouse: Érés.

Miller, J.-A. (2006). La psicosis ordinaria. Buenos Aires: Paidós.

Miller, J.-A. (1997). O método psicanalítico. In J-A. Miller, Lacan elucidado. (pp. 221-268). Rio de Janeiro, RJ: Jorge Zahar. 
Miller, J.-A. (1994). Struc'dure. In J-A. Miller, Matemas II (pp. 89-104). Buenos Aires: Manantial.

Milner, J.-C. (1996). A obra clara: Lacan, a ciência, a filosofia. Rio de Janeiro, RJ: Jorge Zahar.

Milner, J.-C. (2006). As classes paradoxais. In J.-C. Milner, Os nomes indistintos (pp. 89-94). Rio de Janeiro, RJ: Companhia de Freud. (Originalmente publicado em 1983).

Motta, A. (2012). As estruturas não descem às ruas: Lévi-Strauss, mai soixante-huit e o fim do estruturalismo. Revista de Ciências Sociais, (36), 257-266. Recuperado de http://periodicos.ufpb.br/ojs/index.php/politicaetrabalho/article/view/12874

Sales, L. (2007). Passagem da compreensão à verdade: contribuição do estruturalismo à teoria lacaniana da psicose. Ágora: Estudos em Teoria Psicanalítica, 10(2), 211-227. https://doi.org/10.1590/S1516-14982007000200005

Santos, H. (2010). Psicose ordinária, um estudo sobre o desenvolvimento de uma noção. ECOS, 3(1), 160-167. Recuperado de http://www.uff.br/periodicoshumanas/index.php/ecos/article/view/830

Saussure, F. (2006). Curso de linguística geral. São Paulo, SP: Cultrix. (Originalmente publicado em 1916).

Tendlarz, S. (2009). Psicosis, lo clásico y lo nuevo. Buenos Aires: Grama.

Tironi, A. (2010). A psicose ordinária e os inclassificáveis das categorias lacanianas. Opção Lacaniana online, 1(1). Recuperado de http://www.opcaolacaniana.com.br/pdf/numero_1/Psicose_ordinaria.pdf

Vascheto, E., \& Yegatti, E. L. (2008). Conversación con Jean-Claude Maleval. Virtualia, 7(18). Recuperado de http://virtualia.eol.org.ar/018/pdf/miscelaneas_maleval.pdf

Vieira, M. A. (2010). A experiência pelo avesso e o "psiu de luz". Latusa Digital, 7(42-43), 1-4. Recuperado de http://www.latusa.com.br/pdfs/pdf_latusa_digital_42_43_a6.pdf

Viveiros de Castro, E. (2015). Devires do estruturalismo. In E. Viveiros de Castro. Metafísicas canibais (pp. 233-263). São Paulo, SP: Cosac Naify.

Zenoni, A. (2007). Versões do Pai na psicanálise lacaniana: o percurso do ensinamento de Lacan sobre a questão do Pai. Psicologia em Revista, 13(1), 15-26. Recuperado de http://www.pucminas.br/imagedb/documento/ DOC_DSC_NOME_ARQUI20080521171150.pdf

\section{Samira Pontes}

Mestre em Psicologia pelo Programa de Pós-Graduação em Psicologia da Universidade Federal de São João del-Rei (UFSJ). Psicóloga pela UFSJ.

E-mail: spcpontes@gmail.com

\section{Roberto Calazans}

Doutor em Teoria Psicanalítica pela Universidade Federal do Rio de Janeiro (UFRJ). Professor associado II da Universidade Federal de São João del-Rei (UFSJ) e do Programa de Pós-Graduação em Psicologia da UFSJ. Bolsista Produtividade em Pesquisa nível 2 CNPq.

Endereço para envio de correspondência:

Praça Dom Helvécio, n. ${ }^{\circ}$ 74. Fábricas. CEP: 36301-160.

São João del-Rei - MG, Brasil.

Recebido 04/08/2016

Reformulação 28/05/2017

Aprovado 06/06/2017

Received 08/04/2016

Reformulated $05 / 28 / 2017$

Approved 06/06/2017 
Psicologia: Ciência e Profissão Jul/Set. 2017 v. 37 n³, 738-752.

Recebido 04/08/2016

Reformulado 28/05/2017

Aceptado 06/06/2017

Como citar: Pontes, S., \& Calazans, R. (2017). O legado estruturalista em Lacan: clínica e diagnóstico da psicose. Psicologia: Ciência e Profissão, 37(3), 738-752. https://doi.org/10.1590/1982-3703002952016

How to cite: Pontes, S., \& Calazans, R. (2017). The structuralist legacy in Lacan: clinical and diagnostic of psychosis. Psicologia: Ciência e Profissão, 37(3), 738-752. https://doi.org/10.1590/1982-3703002952016

Cómo citar: Pontes, S., \& Calazans, R. (2017). El legado estructuralista en Lacan: clínica y diagnóstico de la psicosis. Psicologia: Ciência e Profissão, 37(3), 738-752. https://doi.org/10.1590/1982-3703002952016 